\title{
Uma intervenção sobre a escrita acadêmica: o que dizem as estudantes de Pedagogia à distância?
}

An intervention on academic writing: what do the e-learning Pedagogy students say?

Rafael Fonseca de Castro*

\author{
Universidade Federal de Rondônia
}

Magda Floriana Damiani**

Universidade Federal de Pelotas

Resumo Este artigo é resultado de uma pesquisa que objetivou investigar a evolução da expressão escrita de acadêmicas de Pedagogia a distância. Durante sete semestres, foram realizadas quatro intervenções e minucioso acompanhamento de seus textos. Os dados foram coletados via análise documental, questionário e entrevista. Das 42 acadêmicas da turma pesquisada, foram intencionalmente selecionadas três para o seguimento da pesquisa. Neste recorte, são descritas as intervenções e apresentados elementos relativos às impressões das acadêmicas sobre as mesmas. Segundo elas: o curso de Pedagogia pouco trabalhou conceitos de língua portuguesa e de produção textual; sentiam-se motivadas ao trabalharem com os conteúdos propostos nas intervenções; receberam positivamente as intervenções e; segundo as próprias e de acordo as análises de seus textos, é possível atestar o aprimoramento efetivo de suas produções textuais.

PALAVRAS-CHAVE: Intervenção; Escrita acadêmica; Pedagogia à distância.

Abstract This article is result of a research that aimed to investigate the evolution of e-learning Pedagogy students' written expression. Throughout seven semesters, there were four interventions and close monitoring of their texts. Data were collected per documental analysis, questionnaire and interview. Of the 42 students from the class we research, were intentionally selected three for the research following-up. In this clipping, the interventions will be described and information concerning the academic views on the interventions will be presented. According to the students: the Pedagogy course bit worked concepts of Portuguese and textual production; they felt motivated on studing the content from the proposed interventions; received positively the interventions; according to their own opinion and to their texts analysis, we can attest to the effective improvement of their textual productions.

KEYWORDS: Intervention; Academic writing; E-learning pedagogy. 


\section{Introdução}

A importância da linguagem escrita para a sociedade é indiscutível. Seu advento marca de forma singular a história da humanidade. Mais do que uma capacidade de registro, essa atividade carrega em si a possibilidade de propiciar benefícios cognitivos inimagináveis antes de seu advento.

A evolução das estruturas gramaticais de línguas e dialetos possibilita que possamos expressar quaisquer informações e sentimentos, em tempos passados, presentes ou futuros, sem fazer uso de sons ou gestos. No entanto, o que se percebe no Brasil, especificamente, é uma série de problemas relacionados a seu uso - como pode ser observado nos estudos de Soares (2008) em relação à educação básica, na pesquisa de Suehiro (2006) sobre o ensino fundamental, nas investigações de Vitória e Christófoli (2013), Damiani et al. (2011) e Ramires (2002) relacionadas ao ensino superior (e em outras publicações diversas sobre o tema) ou em pesquisas de avaliação (IBGE, 2014; INAF 2009; PISA, 2014; SAEB, 2012). Observa-se sérias dificuldades de expressão escrita, inclusive em estudantes de nível superior, o que nos conduz a uma necessária reflexão sobre a qualidade do ensino da escrita no país.

Este artigo é parte de uma pesquisa que, diante deste contexto, objetivou investigar as possibilidades de evolução do exercício da escrita por acadêmicas de um curso de licenciatura em Pedagogia a distância. A investigação compreendeu o período de sete semestres, sendo possível analisar os trabalhos das acadêmicas, desde os primeiros textos, até o trabalho de conclusão de curso (TCC). Neste ínterim, foram realizadas quatro intervenções pedagógicas que visavam ao aprimoramento de suas produções escritas. Tendo como base teórica e metodológica a Psicologia HistóricoCultural, o estudo também pretendeu verificar as impressões das acadêmicas participantes do estudo quanto ao processo interventivo realizado sobre suas escritas.

A pesquisa partiu das seguintes hipóteses: um processo interventivo sistematizado, de uma pessoa mais experiente sobre a escrita de uma menos experiente, tende a contribuir para o aprimoramento da produção escrita desta última; instiga a escrita autorreflexiva; desperta a consciência do escritor sobre o fato de que ele escreve para um interlocutor; alerta para a importância de conhecer as regras gramaticais para uma melhor expressão escrita do pensamento e que; o estabelecimento de uma relação afetiva positiva entre quem realiza a intervenção e quem dela participa é fundamental para o êxito do processo pedagógico interventivo.

Investindo no aprimoramento da capacidade de produção escrita de acadêmicas de um curso superior, especificamente de uma licenciatura em Pedagogia, além de contribuir para o seu desenvolvimento intelectual, estaremos, ao mesmo tempo, melhor capacitando futuras professoras - que serão responsáveis pelo ensino de língua portuguesa em nossas escolas.

\section{Intervindo na escrita acadêmica: perspectivas e implicações}

Para Vygotsky, a linguagem verbal desempenha papel central no ensino e no desenvolvimento dos processos mentais humanos. Segundo este autor (VYGOTSKI, 1931/1995; VYGOTSKY, 1934/1982), o mundo da linguagem permite que nos 
apropriemos (aprendamos) e externemos (comuniquemos ao outro) conhecimentos e informações. Não foi à toa que Vygotsky situou a linguagem em posição central de sua teoria. Ao investigar a relação entre pensamento e linguagem, este pesquisador destacou a linguagem escrita como uma ferramenta cultural de grande importância para o pensamento e para a concepção e o desenvolvimento das funções psíquicas superiores (FPS) (VYGOTSKI, 1931/1995). Segundo o autor, a escrita é "a mais poderosa das linguagens, pois obriga a criança a atuar de uma maneira mais intelectual” (VYGOTSKY, 1934/1982, p. 204).

Contudo, como Vygotsky (1934/1982) apontou, quando se trata de linguagem escrita, é bom lembrar que, para comunicarmos nossas ideias, não contamos com nenhum outro recurso comunicativo: linguagem oral, gestos, mímicas e expressões faciais são todos substituídos pelas regras das línguas. Gramática, pontuação, elementos de coesão e coerência e vocabulário serão nossos suportes para expressar com fidelidade nossos pensamentos.

Bereiter e Scardamalia (1987) explicam que o ato de escrever envolve importantes atividades mentais, tais como estabelecimento de objetivos, planejamento, busca de conteúdos na memória, resolução de problemas, reflexão etc.. Furlanetto (2001) enfatiza que não é fácil compor um texto escrito, mesmo que se trate de um simples bilhete. Por isso, estamos conscientes de que existe uma grande distância entre pensar, falar e escrever. Para Furlanetto (2001), são recorrentes os depoimentos de professores universitários evidenciando que os estudantes têm muito a dizer, mas que nem sempre sabem como fazê-lo de forma adequada, por escrito. Bereiter e Scardamalia (1987) sugerem que, se os estudantes puderem desenvolver habilidades a partir do exercício consciente da escrita, isso deve auxiliá-los a se transformarem em construtores mais ativos de seu próprio conhecimento e melhores escritores.

A presente proposta de intervenção se baseou na premissa de que, ao intervir nos textos das acadêmicas, apontando e exercitando seus problemas e suas dificuldades, elas passariam a tomar consciência destes, podendo, então, controlá-los, melhorando sua expressão escrita. A série de intervenções realizadas integrou uma proposta cujo objetivo era promover mudanças, como nos moldes apontados por Luria (1992), na forma da produção da escrita das estudantes, na busca pela melhor expressão das ideias:

A mudança do objetivo de uma tarefa leva inevitavelmente a uma mudança significativa na estrutura dos processos psicológicos que a levam a termo. Uma mudança da estrutura da atividade, em outras palavras, implica uma mudança na organização cerebral dessa atividade (p. 176).

Segundo Vygotski (1925/1991; 1931/1995), é necessário que tenhamos consciência sobre uma determinada ação cognitiva para que possamos controlá-la. Em termos de linguagem escrita, é preciso que tenhamos consciência dos problemas e de suas implicações para que possamos controlá-los e corrigi-los. Ao longo das intervenções, objetivou-se alertar as acadêmicas sobre suas principais dificuldades de escrita para que pudessem refletir sobre a natureza das mesmas, com vistas a entendê-las e na busca por superá-las. 
Todavia, há um receio natural frente a este tipo de ação pedagógica, tendo o apontamento do erro como força motriz das intervenções. Erro que, na sociedade extremamente competitiva atual, é naturalizado como algo negativo. Em termos de escrita, errar é, obviamente, prejudicial ao ato comunicativo, no entanto, somente tomando consciência dos erros de escrita é que poderemos superá-los. Além disso, trabalhar o erro na escrita desencadeia uma série de estratégias cognitivas reflexivas que, na perspectiva vygotskiana, estimula o desenvolvimento intelectual consciente.

Como as acadêmicas irão reagir às marcações em seus textos? Isso afetará negativamente sua autoestima com relação à escrita? Acadêmicas que erram bastante irão ter maturidade suficiente ao lidarem com os erros e efetivamente melhorar suas escritas? Deparamo-nos com uma série de questionamentos neste sentido ao longo das intervenções. Em cada novo contexto empírico, as respostas a esses questionamentos poderão variar. As pessoas reagem de formas diferentes a este tipo de abordagem e procuramos criar um ambiente positivo, baseado no diálogo horizontal alicerçado na perspectiva didática de co-construção do conhecimento (WELLS, 2001).

\section{Métodos de pesquisa}

Tratou-se de uma pesquisa qualitativa, com duração de sete semestres (de 2009/2 a 2012/2), considerando, como defendia Vygotsky (1931/1995), o desenvolvimento de um processo, não atentando apenas a seu início e seu fim. Todo o processo investigativo foi realizado on-line ${ }^{1}$ e os instrumentos de coleta de dados utilizados foram análise documental, questionário e entrevista (GIL, 2010). A análise de dados ancorou-se na análise textual e discursiva, proposta por Moraes (2003).

A pesquisa do tipo intervenção pedagógica está fundamentada a preceitos histórico-culturais e se baseia na perspectiva metodológica defendida por Damiani et al (2014), cujo objetivo é gerar conhecimento para a aplicação prática e/ou dirigidos à solução de problemas educacionais concretos específicos. Estes pesquisadores defendem o uso do termo intervenção para denominar pesquisas na área pedagógica que se baseiem em mudanças introduzidas em processos educacionais, com base em um dado referencial teórico e com o propósito de melhorar tais processos, avaliados ao final.

A turma pesquisada era vinculada a um curso de licenciatura em pedagogia a distância, integrante da Universidade Aberta do Brasil (UAB). A turma foi selecionada intencionalmente em virtude de o pesquisador atuar como seu professor durante três semestres No o início do estudo, havia 42 acadêmicas. Destas, 32 concluíram o curso, colando grau como licenciadas em pedagogia e professoras habilitadas para atuarem na Educação Infantil, anos iniciais do Ensino Fundamental e Educação de Jovens e Adultos (EJA). Foram intencionalmente selecionadas três acadêmicas para o seguimento da pesquisa: Annia, Branka e Yeva². A opção por essas estudantes considerou suas diferentes competências no domínio da escrita, além da disponibilidade em participarem do estudo e de interagirem on-line com o professor-pesquisador. 


\section{Descrição das intervenções}

Foram realizadas quatro intervenções: 1 . Introdução, desenvolvimento e conclusão: intervindo na macroestrutura dos textos acadêmicos (2010/1); 2. Orientação da escrita de resumos e artigos (2011/2); 3. Oficina de Escrita: "Eu escrevo, mas será que eles entendem?" (2012/1) e; 4. Ambiente Virtual de Apoio à escrita (AVA-e): Escrevendo o TCC (2012/2).

Inicialmente, foi realizada uma análise dos textos escritos pelas estudantes, ao longo dos dois primeiros semestres do curso, com o intuito de compor um panorama geral de suas dificuldades de escrita, sendo classificadas em três níveis: 1) muita; 2) média; e 3) pouca. Para tanto, foram adotados critérios amplos, como clareza das ideias e existência de um "fio condutor" na argumentação; e levadas em consideração premissas básicas da progressão textual (KOCH, 2003) e do texto argumentativo (CITELLI, 1994; PERELMAN, 2005). Da turma, 27 acadêmicas foram classificadas nos grupos 'muita dificuldade' ou 'dificuldade média'. Esses dois níveis, juntos, compreenderam $60 \%$ da turma. Do total, apenas 14 acadêmicas demonstravam pouca dificuldade de escrita. Especificamente com relação às três estudantes selecionadas para o seguimento da pesquisa, Annia foi classificada como apresentando muita dificuldade, Branka apresentando dificuldade média e, Yeva, com poucas dificuldades de escrita.

A partir deste quadro inicial, ficaram evidentes deficiências de natureza variada, sendo, as principais, relativas à organização macroestrutural dos textos, ao não uso e/ou uso equivocado de conectivos e ao emprego incorreto de recursos de pontuação. Essas informações serviram de base para o planejamento das intervenções.

No segundo semestre do curso de Pedagogia, foi considerada como imperiosa, pelo colegiado de professores, a necessidade de as estudantes de todos os polos do curso aprimorarem a estrutura e a organização de seus textos, visando a melhor exposição de ideias. Como consequência dessa percepção, foi planejada a Intervenção 1. Partindo da premissa de que um texto deve ser claro ao tratar da defesa de qualquer argumento, a perspectiva de texto argumentativo (CHARAUDEAU, 2008) propõe que deva ser constituído de: 1) uma introdução, para apresentar o tema, a tese que será defendida e seus objetivos; 2) um desenvolvimento, no qual o autor opina, apresenta informações pertinentes, ideias e argumentos e; 3) uma conclusão, que feche as ideias apresentadas no desenvolvimento. Decidiu-se, então, que todos os trabalhos das acadêmicas, a partir daquele momento do curso, deveriam ser estruturados com "introdução, desenvolvimento e conclusão", conforme orientações de Charaudeau (2008) e Citelli (1994).

A Intervenção 2 esteve voltada à redação de resumos e de artigos. Teve duração de três meses, com início no primeiro semestre de 2011. As acadêmicas teriam que resumir um texto que haviam escrito no semestre anterior, com objetivo de trabalhar especificamente a síntese de ideias. $\mathrm{Na}$ sequência da Intervenção 2, cada acadêmica deveria escrever um artigo, relativo a uma entre três temáticas: aprendizagem, gestão escolar ou prática pedagógica (conforme orientação do curso). As estudantes foram orientadas por meio das Salas de Orientação (fóruns criados para o diálogo entre 
orientador e orientandas), pelos espaços de envio de arquivo/feedback e via chats. Desta forma, havia uma série de recursos para a efetivação do diálogo com as acadêmicas, ao longo dessa intervenção.

Os resumos e os artigos postados pelas acadêmicas eram lidos, analisados e reenviados às mesmas pelo orientador. Nesse movimento de retro-colaboração, por meio de envio de arquivos e feedbacks, o número de postagens (pelas acadêmicas) e de feedbacks (pelo pesquisador) variava de acordo com a evolução do texto de cada estudante.

As incursões diretas nos arquivos dos textos das acadêmicas consistiam em marcações de quatro tipos, correspondendo às seguintes mensagens: retirar (fonte em vermelho), sugestões do pesquisador para aprimorar uma ideia construída (grifo em azul), alerta para trecho equivocado ou confuso (grifo em amarelo) e comentários (utilizando a ferramenta Comentários do editor de textos). A figura 1, relativa a um feedback para Branka, na Intervenção 2, ilustra a legenda estabelecida para as acadêmicas identificar as incursões em seus textos:

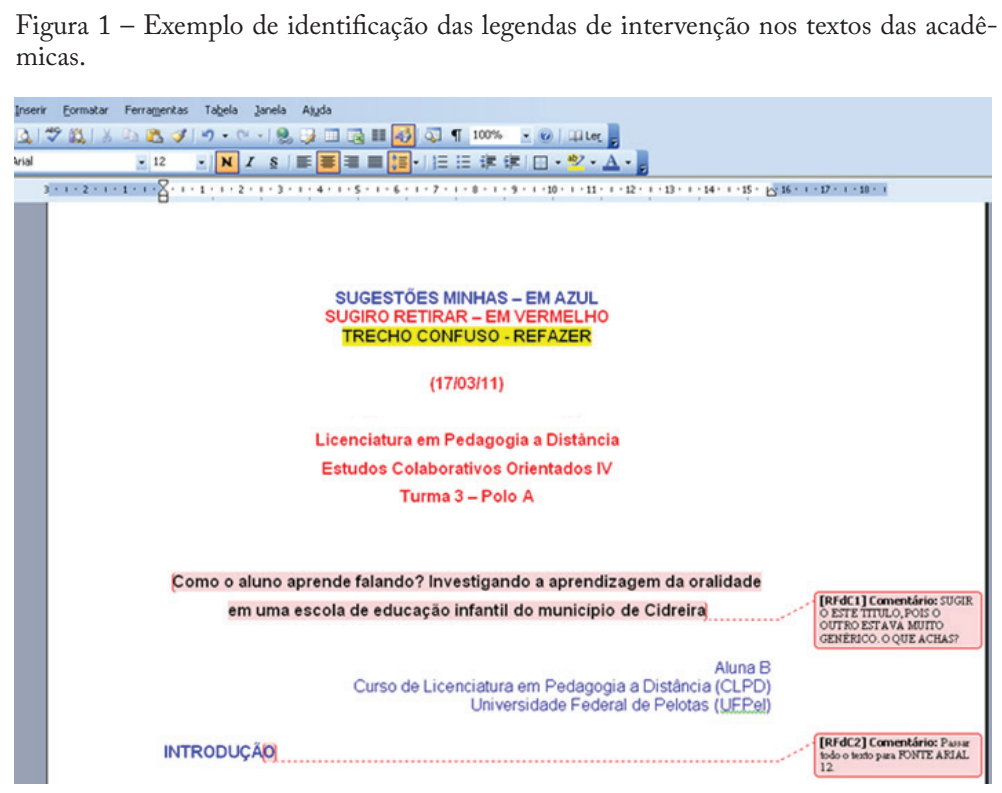

Era explicado que, ao retirarem os trechos em vermelho, as ideias expostas, além de não perderem o sentido, tornavam-se mais objetivas e, consequentemente, de mais fácil entendimento. A intenção deste tipo de intervenção é despertar a consciência do escritor sobre trechos considerados repetitivos ou escritos de maneira confusa.

As incursões em azul visavam a sugerir formas mais adequadas de argumentação das ideias expostas originalmente. Tendo como pressuposto teórico o conceito vygotskiano de imitação (VYGOTSKI, 1931/1995), este tipo de intervenção intencionava demonstrar e sugerir formas mais adequadas de expressão escrita; e que pode- 
riam despertar consciência nas acadêmicas dos problemas que seus textos apresentavam e, talvez, concomitantemente, servir de modelo para uma escrita mais adequada. As intervenções pontuais nos artigos foram guiadas pelas ideias de diferentes autores, acerca dos níveis macro e micro estruturais do texto (CITELLI, 1994; CHARAUDEAU, 2008), paragrafação e progressão textual (KOCH, 2003); articuladores textuais (KOCH, 2003; 2010) e coesão por referência (CITELLI, 1994; KOCH, 2006) e; pontuação (LUKEMAN, 2011).

Os grifos em amarelo, por sua vez, buscavam prover maior autonomia às acadêmicas na revisão dos textos, propiciando momentos de autorreflexão a partir de trechos apontados como confusos. Diferentemente das marcações em vermelho, não eram acompanhadas de comentários a respeito dos problemas da escrita. Elas deveriam repensar, por si próprias, sobre a forma como aquelas ideias estavam expostas, buscar alternativas para melhor expressá-las e reescrevê-las.

O recurso 'Comentário' do editor de textos foi utilizado nos casos em que era necessário explicar aspectos relacionados ao conteúdo e à forma dos textos, possibilitando a escrita de orientações "dentro do arquivo, mas fora do texto".

A Intervenção 3 apresentou características diferentes das outras, pelo fato de ser organizada fora do currículo regular do curso de Pedagogia e por ser estruturada com foco exclusivo na linguagem escrita. Denominada Oficina de Escrita, baseou-se na revisão de textos e no estudo de conteúdos de língua portuguesa e produção textual. A intenção era levar as acadêmicas a refletir sobre erros de escrita e buscar corrigi-los, aprimorando-os. A Oficina foi oferecida no mês de janeiro do ano de 2012, com carga-horária de 40 horas, em 21 dias e com a participação de 20 acadêmicas de quatro polos (turmas) diferentes do curso.

O layout do ambiente Moodle foi customizado de forma a estimular as participantes da oficina quanto à estreita relação entre pensamento e escrita (figura 2):

Figura 2 - Layout da Oficina de Escrita no ambiente Moodle

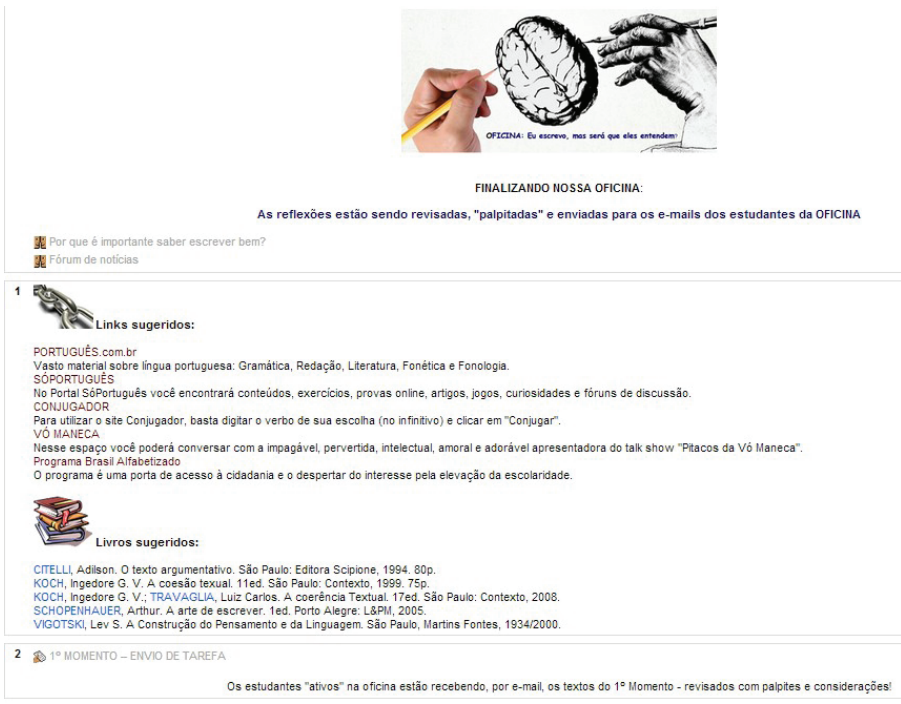


Além dos fóruns e dos espaços para envio de arquivos/feedbacks, ao longo da oficina, foram fornecidos conteúdos de língua portuguesa: links de sites sobre português, recursos didático-pedagógicos on-line e dicas de livros sobre escrita (figura 2).

A oficina foi dividida em seis momentos: $1^{\circ}$ Momento - Envio de Arquivo - "Texto inicial", 20 Momento - Fórum de Discussão: "Enxergando nossas dificuldades para superá-las", $3^{\circ}$ Momento - Envio de Arquivo: "Agora você é o revisor", $4^{\circ}$ Momento - Fórum de Discussão: "Agora você é o revisor", $5^{\circ}$ Momento - Fórum de Discussão: "Que escrita é essa?" e Reflexão Final - Envio de Arquivo: "Vamos exercitar o que aprendemos?". A atividade combinou intensos momentos de debates em fóruns e atividades interventivas diretamente sobre os textos das participantes, envolvendo as temáticas macroestrutura textual, pontuação, uso da crase, regência verbal, coesão e coerência e trabalho constante com base na análise reflexiva de erros de escrita.

A Intervenção 4 foi realizada durante a escrita do TCC, pelas acadêmicas Annia e Yeva (que participaram das intervenções 1 e 3) e Branka (que participou das intervenções 1 e 2). Para esta intervenção, foi criado um AVA especialmente para conduzir o trabalho interventivo: o Ambiente Virtual de Apoio à escrita (AVA-e) (figura 3):

Figura 3 - Layout AVA-e: Ambiente Virtual de Apoio à Escrita

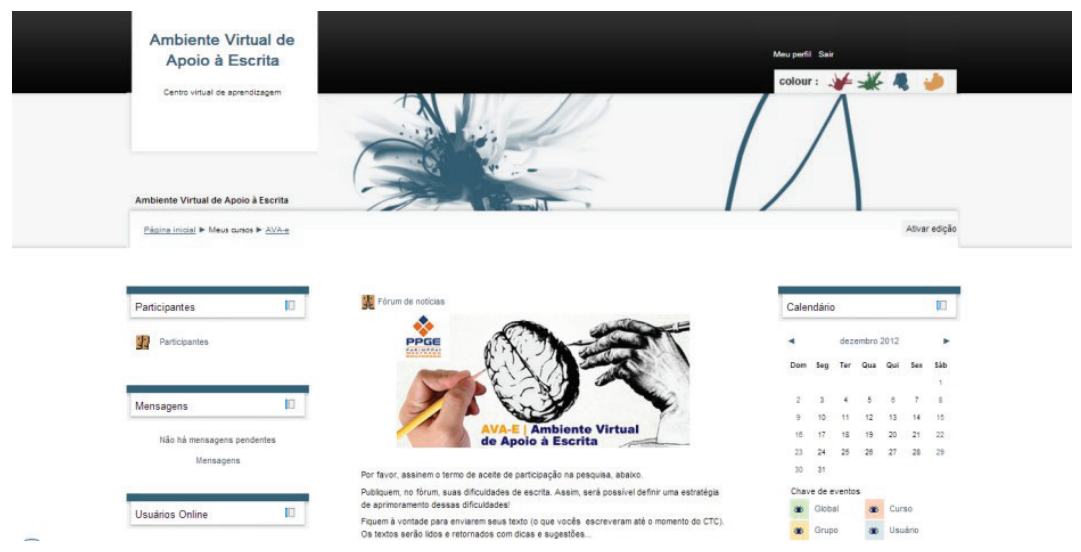

O foco das incursões esteve centrado em dificuldades de escrita detectadas previamente nos textos de Annia, Branka e Yeva: organização macroestrutural, uso de articuladores textuais e pontuação. O AVA-e continha dois espaços de interação: um Fórum Geral e um espaço destinado ao envio de arquivo/feedbacks, pelo qual as acadêmicas postavam versões do TCC e recebiam os feedbacks. As acadêmicas foram formalmente orientadas por tutoras a distância do curso de Pedagogia e, paralelamente, por meio do AVA-e, com o pesquisador, tinham a oportunidade de trabalhar mais profundamente a parte escrita (sem desvincular forma de conteúdo). Nos feedbacks sobre os TCC, fora usado o mesmo sistema de cores utilizado nas intervenções 2 e 3 . Nesta intervenção, foi possível realizar o trabalho intenso sobre os textos de Annia, Branka e Yeva - culminando nas versões finais de seus TCC. 


\section{Os achados}

A análise dos achados da investigação possibilitou que os efeitos das intervenções fossem avaliados. Serão apresentados, a seguir, elementos relativos às reações das acadêmicas às intervenções pedagógicas.

$\mathrm{Na}$ entrevista realizada no último ano do curso de Pedagogia, as acadêmicas foram perguntadas sobre o trabalho do curso relativo a conteúdos de língua portuguesa. Os depoimentos de Yeva e Branca convergem com o que foi possível observar ao longo da participação do professor-pesquisador no referido curso de Pedagogia. Yeva foi direta ao responder que não houve ensino direcionado nesse sentido, mas relativizou sua resposta sugerindo que não lhe fez falta:

Yeva - Direcionado não. Com muito enfoque neste sentido não. Penso que a preocupação do curso era mais voltada para os conteúdos específicos da área de Licenciatura em Pedagogia, mesmo assim sempre fomos alertados que lemos mais, revisássemos nossa escrita.

Branka, por sua vez, foi enfática, demonstrando acreditar que deveria ter sido mais cobrada pelo curso nesta área e que se recente até hoje da falta do curso com relação aos conteúdos de ortografia, gramática e linguística:

Branka - Mais ou menos acho que deveria haver mais cobranças, mais ortografia, mais gramatica [...] é importante o ensino de língua portuguesa em cursos de pedagogia. Me sinto preocupada as vezes em fazer uma anotação na agenda do meu aluno e os pais verem o prof escrevendo errado, [no] meu diario de planejamento também.

Para Branka, a lacuna parece ser latente, já que, ao responder a primeira questão da entrevista on-line 'Comente um pouco sua experiência como estudante de um curso de $\mathrm{EaD}$ (aspectos positivos e negativos de estudar a distância)', sua primeira escolha para ponto negativo foi a falta de conteúdos teóricos ao longo do Curso:

Branka - [...] um ponto negativo acho que faltou mais teoria pois tivemos muitas praticas durante o curso. Hoje como profissional sinto falta de mais amparo teorico, outros [autores] além de Freire.

Com relação ao ensino de língua portuguesa, Sforni (2004) defende que o acesso aos sistemas ortográficos, linguísticos e gramaticais permite ao estudante tomar consciência de sua própria atividade como usuário da língua e, assim, alcançar um nível superior no desenvolvimento da linguagem. A apropriação dos sistemas gramaticais, todavia, não é espontânea, exige mediação intencionalmente organizada, fundamentalmente, via educação formal. Para Davydov (1988), a gramática e a linguística devem ser trabalhadas com o educando ao ponto que se tornem necessárias à realização de suas ações.

No decorrer das intervenções, foram disponibilizados conteúdos de língua portuguesa e produção textual, com a intencionalidade de poder promover justamente a relação entre teoria e prática. Questionadas sobre o uso desses recursos nas intervenções, na entrevista on-line, elas assim se manifestaram: 
Annia - Teve um livro que gostei muito que era a arte de escrever [de Arthur Schopenhauer] onde aprendi a expor em papel tudo o que pensava e tinha em pensamento, como ideias para realização pros trabalhos a seguir. $\mathrm{Na}$ verdade usei o livro que estudei sobre a importancia da escrita e alguns trabalhos que fiz durante o curso que o senhor me avaliava e os textos me dizendo o que deveria refazer foi onde me ajudou bastante pois ali mostrou que deveria entender o que escrevia.

Branka - Utilizei "os porquês" e o material sobre os verbos que me indicou. [...] Foi bem util no meu trabalho, a regra dos porquês quero dizer.

Yeva - Não lembro o nome dos sites disponibilizados na oficina [Intervenção 3], mas gostei daquele que dá para fazer a conjugação dos verbos, também teve um material que falava sobre coesão e coerência $[. .$.$] outro bem importante foi quanto ao uso da vírgula, tema$ sobre o qual até realizamos um fórum [...] E se não engano teve um também é um dicionário virtual.

É gratificante saber que todas utilizaram parte do material disponibilizado. Foi perceptível, nas orientações dos artigos (Intervenção 2), na Oficina de Escrita (Intervenção 3) e na escrita do TCC (Intervenção 4), motivação por parte das estudantes ao trabalharem com conteúdos de língua portuguesa e escrita. Elas pareciam querer realmente estudá-los e aprender mais com eles.

Especificamente sobre a abordagem nas intervenções, Annia, Branka e Yeva avaliaram este quesito da seguinte forma:

Annia - Suas opiniões foram de muita importancia pra mim, pois a cada trabalho que fazia comecei a compreender o que tinha a melhorar me dando crescimento pra seguir em frente, pois colocava no papel o que vinha na minha mente, tudo o que desejava a falar, não me preocupando se estava correto. $\mathrm{E}$ a cada vez que mandava o texto ficava ansiosa pra que tu me mandasse o feed, pois sabia que poderia crescer atraves dele.

Branka - Sempre foi positivo, pois me senti realmente orientada, sabia que realmente tinha lido meu trabalho e dado muita importancia a ele e assim realizar todas as colocações e marcações [...] Eu vou ser grata por toda a minha vida! Por mais que a minha tutora me orientava, mas não me sentia totalmente amparada, com a sua ajuda ficou mais claro, justamente pelas colocações.

Yeva - Sempre me identifiquei muito contigo e gostaria de saber tanto quanto tu sabes sobre "escrita", mas lembro que tu sempre me elogiavas quanto à minha escrita, ao mesmo tempo davas o teus "pitacos" a fim de que reavaliasse alguns pontos [...] Ter um acompanhamento mais individual foi muito importante naquele momento crucial de final de curso com o TCC.

Os três relatos acenam para o recebimento positivo das intervenções. Podemos conferir a boa aceitação à proposta pedagógica interventiva à relação afetiva e de confiança desenvolvida entre o professor/pesquisador e as acadêmicas ao longo da pesquisa. 
Quanto ao despertar da consciência dos erros de escrita, utilizaram recorrentemente, em suas manifestações, expressões como "clareou minhas ideias" e "me ajudou muito", revelando indícios de êxito da proposta de trabalho baseada no erro e na ajuda, defendida por Wells (2001), incorporada às intervenções. Na Intervenção 3 (Oficina de Escrita), trouxeram exemplos de erros de escrita percebidos a partir das intervenções em seus textos, revelando conscientização dos mesmos.

De um modo geral, as acadêmicas, inicialmente, ao perceberem a série de "apontamentos coloridos" em seus textos, ficavam temerosas, pois, provavelmente, não tinham consciência do grau de deficiência que apresentavam em suas escritas. Contudo, demonstraram maturidade ao trabalharem com suas dificuldades, buscando sempre superá-las. Analisando particularmente cada acadêmica, Annia relatou que passou a compreender mais claramente o que tinha que melhorar; Branka ressaltou o fato de se sentir mais segura, pois percebia o que precisava aprimorar e; Yeva revelou que foi muito bom poder contar com uma análise mais criteriosa de seus textos.

Com o passar dos semestres, a estrutura dos textos foi sendo aprimorada, culminando em TCC dotados de macroestrutura textual muito boa, nos casos de Annia e Branka, e, excelente, no caso de Yeva. Contudo, ao final da análise deste quesito, ficou latente a necessidade de maior embasamento teórico sobre conceitos linguísticos que contribuiriam para a melhora no que se refere ao fluxo da argumentação.

No que se refere à categoria uso de articuladores textuais, os resultados evidenciam melhora nos textos de Annia, Branka e Yeva, desde os primeiros textos, até a versão final de seus TCC, cabendo destaque os quesitos: 'maior uso de articuladores textuais' e 'aumento do repertório de articuladores textuais utilizados'. O expressivo uso de locuções conjuntivas, pelas três estudantes, em seus TCC, foi outro fator positivo. Todas demonstraram buscar conectar suas ideias com relevante frequência por meio desse recurso. Contudo, os números absolutos e proporcionais de empregos equivocados de articuladores textuais também merecem destaque. Mesmo a análise desta categoria tendo gerado evidências de avanço das três acadêmicas quanto ao seu uso, nos TCC, ainda foi perceptível a falta de conhecimento teórico acerca do uso de alguns deles.

$\mathrm{Na}$ categoria pontuação, também foram percebidos avanços importantes ao final do curso. Os períodos excessivamente longos (problema evidenciado na escrita de todas as acadêmicas da turma pesquisada) diminuíram, mas ainda não é possível afirmar que as três acadêmicas dominam os conceitos de oração e período, por exemplo. Mais difícil, considerar que detêm a percepção das sutilezas da língua que envolvem a escolha dos tamanho de períodos para a produção de sentidos ao longo de uma argumentação, como explicita Lukeman (2011).

\section{Considerações finais}

A partir dos resultados encontrados, a pesquisa sugere que o curso de Pedagogia pouco trabalhou conteúdos de língua portuguesa e produção escrita; que as acadêmicas se sentiam motivadas ao trabalharem com esses conteúdos; que as inter- 
venções foram recebidas positivamente por elas e; que os problemas de escrita presentes até o fim do curso poderiam ter sido superados com a apropriação de conceitos básicos de língua portuguesa aplicados à produção textual. Somamo-nos à opinião de Sforni (2004) quando esta defende que a formação de professores implica também a capacidade de pensar teoricamente as situações de ensino, sendo este o diferencial profissional do educador.

Muito se sabe sobre os problemas do domínio da escrita pelos estudantes brasileiros. Muitas pesquisas revelam defeitos e virtudes no ensino da escrita. E muito do que é produzido na academia precisa se corporificar na prática educativa. Sendo assim, defendemos mais propostas interventivas, em todos os níveis educacionais, com vistas à melhora deste preocupante quadro. Não obstante, temos ciência das dificuldades para se realizar trabalhos com graus de intensidade como o realizado, em se tratando de turmas grandes nas escolas e em meio a jornadas duras de trabalho dos professores da educação básica.

Por fim, superadas essas dificuldades, sugerimos que uma pessoa com dificuldades para escrever, com a ajuda de uma pessoa mais experiente, pode superar suas dificuldades e se tornar uma boa escritora, quiçá, uma ótima escritora. No contexto educacional, quem mais indicado para tal do que o professor?

\section{Referências}

BEREITER, C.; SCARDAMALIA, M. The Psychology of Written Composition. New Jersey: Lawrence Erlbaum Associates, 1987.

CHARAUDEAU, P. Linguagem e Discurso - modos de organização. São Paulo: Contexto, 2008.

CITELLI, A. O texto argumentativo. São Paulo: Editora Scipione, 1994.

DAMIANI, M. F. et al. A escrita acadêmica: análise e intervenção. Pelotas: Linguagem $\boldsymbol{\&}$ Ensino, v. 14, n. 1, p. 249-271, ju1/dez 2011.

DAMIANI, M. F. et al. Sobre pesquisas do tipo intervenção. Pelotas: Cadernos de Educação, v. 45, n. 1, 2014.

DAVYDOV, V. V. La enseñanza escolar y el desarrollo psíquico. Havana: Editorial Progresso. 1988.

FURLANETTO, M. M. Tenho um trabalho na cabeça. Linguagem em Discurso, Florianópolis, v. 1, n. 1, p. 13-24, 2001.

GIL, A. C. Como elaborar projetos de pesquisa. 5 ed. São Paulo: Editora Atlas, 2010.

IBGE. Instituto Brasileiro de Geografia e Estatística. Disponível em: <http://www.ibge.gov. br/home/>. Acesso em: 12 jun. 2014.

INAF. Indicador de Alfabetismo Funcional. São Paulo: Ação Educativa, 2009.

KOCH, I. G. V. A coesão texual. 22 ed. São Paulo: Contexto, 2010.

. Argumentação e linguagem. 10 ed. São Paulo: Cortez, 2006.

. Desvendando os segredos do texto. 2 ed. São Paulo: Cortez, 2003.

LUKEMAN, N. A arte da pontuação. Trad.: Marcelo Dias Almada. São Paulo: Martins Fontes, 2011. 
LURIA, A. R. A construção da mente. Ícone: São Paulo, 1992.

MORAES, R. Uma tempestade de luz: a compreensão possibilitada pela análise textual discursiva. Ciência e educação. Bauru, v. 9, n. 2, p. 191-211, 2003.

PERELMAN, C. Tratado da Argumentação: a nova retórica. 2 ed. São Paulo: Martins Fontes, 2005.

PISA. Programme for International Student Assessment. Disponível em: <http://www.oecd. org/pisa/>. Acesso em: 12 jun. 2014.

RAMIRES, V. Leitura e produção escrita de universitários. Fortaleza: Revista de Letras, vol. $1 / 2$, n. 24, p. 34-42, 2002.

SAEB. Sistema de Avaliação da Educação Básica. Disponível em: <http://portal.inep.gov.br/ saeb>. Acesso em: 21 jan. 2012.

SFORNI, M. S. de F. Aprendizagem conceitual e organização do ensino: contribuições da teoria da atividade. Revista Teoria e Prática da Educação, v. 7, n. 1, p. 120-132, 2004.

SOARES, M. Alfabetização e Letramento. 5 ed. São Paulo: Contexto, 2008.

SUEHIRO, A A. C. Dificuldade de aprendizagem da escrita num grupo de crianças do ensino fundamental. São Paulo: PSIC - Revista de Psicologia da Vetor Editora, v. 7, n. 1, p. 59-68, 2006.

VITÓRIA, M. I. C.; CHRISTÓFOLI, M. C. P. A escrita no Ensino Superior. Revista Educação, Santa Maria, v. 38, n. 1, jan./abr. 2013, p. 41-54.

VYGOTSKI. L. S. Obras Escogidas Tomo I (La consciencia como problema de la psicología del comportamiento). Madrid: Aprendizaje Visor y Ministerio de Educación y Ciencia, 1925/1991.

Obras Escogidas Tomo III (Historia del Desarrollo de las Funciones Psíquicas Superiores). Madri: Visor, 1931/1995.

VYGOTSKY, L. S. Obras Escogidas Tomo II (Pensamiento Y Lenguaje). Moscú: Editorial Pedagógica, 1934/1982.

WELLS, G. Indagación Dialógica: hacia una teoría y una práctica socioculturales de la educación. Barcelona: Paidós, 2001.

\section{Notas}

\footnotetext{
${ }^{1}$ As intervenções foram realizadas via ambiente virtual Moodle (Modular Object-Oriented Dynamic Learning Environment). O Moodle é o ambiente virtual mais utilizado no Brasil, inclusive, em cursos vinculados à UAB.

${ }^{2}$ Optamos por não revelar a cidade-polo da turma pesquisada, tampouco, os nomes das acadêmicas (identificadas por nomes russos), por razões de confidencialidade.
} 
Rafael Fonseca de Castro - Magda Floriana Damiani

\section{Correspondência}

Rafael Fonseca de Castro - Universidade Federal de Rondônia, Núcleo de Ciência da Educação. Campus - BR 364, Km 9,5. CEP: 76801059. Porto Velho, Rondônia, Brasil.

E-mail: rafaelfdecastro@gmail.com - flodamiani@gmail.com

Recebido em 21 de maio de 2016

Aprovado em 19 de julho de 2016 